\title{
The Prevalence of Resistant Hypertension Among Type 2 Diabetic Patients Attending the National Center for Diabetes, Endocrinology, and Genetics
}

\author{
Abeer Mohammad $^{\mathrm{a}}$, Mousa Abujbara ${ }^{\mathrm{a}}$, Jafar Alshraideh ${ }^{\mathrm{b}}$, Hashem Jaddouc, \\ Kamel Ajlouni ${ }^{\mathrm{a}, \mathrm{d}}$
}

\begin{abstract}
Background: In type 2 diabetic patients, resistant hypertension (RH) is associated with higher cardiovascular diseases (CVDs) and renal diseases; however, a prevalence of RH in the Middle East is unknown. Long duration of uncontrolled blood pressure and diabetes may increase the risk of $\mathrm{RH}$. This study aimed to assess the prevalence of hypertension and $\mathrm{RH}$ among adult type 2 diabetic patients, and to determine the relationship between $\mathrm{RH}$ and patient demographics.
\end{abstract}

Methods: A cross-sectional study was conducted from December 25, 2015 to the end of January 2016 at the National Center for Diabetes, Endocrinology, and Genetics (NCDEG) in Amman, Jordan. A total of 1,106 type 2 diabetic patients were recruited. Data were obtained directly from the patients and patient medical file using a pre-prepared data collection sheet. Patients were considered to be hypertensive according to the physician's diagnosis on patient medical files, and hypertensive patients were considered to have $\mathrm{RH}$ if systolic blood pressure was $\geq 140 \mathrm{~mm} \mathrm{Hg}$ and/or diastolic blood pressure was $\geq$ $90 \mathrm{~mm} \mathrm{Hg}$ even using three antihypertensive medications or patients who had blood pressure $<140 / 90 \mathrm{~mm} \mathrm{Hg}$ but using four medications or more. Chi-square test was used to compare categorical differences, and logistic regression was used to calculate the adjusted odds ratio.

Results: In the study subjects, $53 \%$ were females. The mean age was $60 \pm 10.41$ years (mean \pm SD), $66 \%$ had poor glycemic control, $47 \%$ had long-standing diabetes for 10 years or more, and $93 \%$ were obese and overweight. The overall prevalence of hypertension was $79.6 \%$ $(\mathrm{n}=880)$, and the prevalence of $\mathrm{RH}$ was $12 \%$ among type 2 diabetic patients and $16 \%$ among diabetic hypertensive patients $(n=141)$. Logistic regression analysis revealed that increasing age, obesity, longstanding hypertension, hypertension controlling, and CVDs were sig-

Manuscript submitted August 17, 2017, accepted September 12, 2017

${ }^{a}$ The National Center (Institute) for Diabetes, Endocrinology and Genetics, University of Jordan, Amman, Jordan

bSchool of Nursing, University of Jordan, Amman, Jordan

'Department of Epidemiology and Public Health, The Jordan University of Science and Technology (JUST), Irbid 22110, Jordan

${ }^{\mathrm{d} C o r r e s p o n d i n g ~ A u t h o r: ~ K a m e l ~ A j l o u n i, ~ T h e ~ N a t i o n a l ~ C e n t e r ~(I n s t i t u t e) ~ f o r ~}$ Diabetes, Endocrinology and Genetics, University of Jordan, PO Box 13165, Amman 11942, Jordan. Email: ajlouni@ju.edu.jo

doi: https://doi.org/10.14740/jem448e nificantly correlated with RH.

Conclusion: The prevalence of $\mathrm{RH}$, among adult type 2 diabetic patients, was $16 \%$; older age, obesity, long duration and poor blood pressure control and CVD were significantly and positively associated with RH. RH is a serious problem which could worsen complications due to diabetes and hypertension, thus increased awareness is needed for patients and medical team about $\mathrm{RH}$ and its risk factors.

Keywords: Hypertension; Diabetes; Cardiovascular disease

\section{Introduction}

Hypertension (HTN) is the world's leading attributable cause of death, affecting an estimated 1.2 billion people worldwide [1]. It is commonly observed in patients with cardiovascular diseases (CVDs) that blood pressure remains abnormally elevated for a long term period $[2,3]$. Often asymptomatic when left untreated, chronic HTN can significantly increase the risk of heart attack, stroke, heart failure, kidney disease and death, posing serious health risks to those suffering from the disease [4]. HTN is a main public health challenge worldwide, affecting $20 \%$ of the world population [5]. Prevalence of HTN among type 2 diabetic patients is $70-80 \%$ [6]. Poor blood pressure control among diabetic patients is associated with increasing risk of CVD events and mortality [7]. Blood pressure for diabetic patients should be less than 140/90 mm $\mathrm{Hg}$ [8]. Achieving blood pressure control for diabetic patients is difficult, and $50 \%$ of type 2 diabetic patients have uncontrolled blood pressure $[5,9]$. Poor blood pressure control is associated with resistant hypertension (RH) [10]. RH is present in about one of eight hypertensive patients [11]. Researches suggest that $28 \%$ of treated hypertensive individuals are considered resistant to treatment, and these patients have a threefold increase in risk of CVD events compared to individuals with controlled hypertensive patients [12]. Additionally, they are more likely to have diabetes, chronic kidney disease, and obesity $[10,12,13]$. Studying the prevalence of RH among diabetic patients and its associated factors will establish a database about the size and the effect of this health problem that will help clinicians to plan for preventing and managing RH among these patients. According to "National health and nu- 
trition examination survey (NHANES)", which was a multistage sampling design study in $2003-2008$, RH in the USA is more prevalent with the prevalence from $8.9 \%$ in 2003 to $20.7 \%$ in 2008 [14]. Also another large study conducted in North America and Europe showed that the prevalence of $\mathrm{RH}$ among $>600,000$ hypertensive patients was $14.8 \%$ [15]. In a large cross-sectional study conducted in Spain, "The reproducibility of albuminuria in type 2 diabetes patients (RIACE) study", about 15,773 diabetic patients consecutively visiting 19 diabetes clinics during the years 2007 - 2008 were enrolled to the study. RH was detected in 2,363 , accounting for $15 \%$ of the population sample and $17.4 \%$ of hypertensive diabetic patients [16]. Also in a retrospective observational study conducted in Italy, it was 10\% [17]. Another analysis study was conducted to evaluate clinical differences between $\mathrm{RH}$ patients and patients controlled on three or less drugs, and they found that those with RH had a higher prevalence of diabetes mellitus of $18.8 \%$ versus $3.5 \%$ among patients treated and controlled with three or less [18]. In a Japanese cross-sectional study, it was found that among 1,737 type 2 diabetic patients who were included in the study in 2015, the prevalence of $\mathrm{RH}$ was $21.8 \%$ [19]. Many studies reported that there are common associated factors with RH like aging, CVDs, diabetes, obesity, and renal dysfunctions [18-20].

\section{Methodology}

A cross-sectional design was used to collect data from patients attending the diabetes clinic at the NCDEG during the period from November 2015 to the end of January 2016. This center is a specialized center for diabetes, which was established in 1996 in Amman. Ethical approval for conducting the study was obtained from the Ethics Committee at the NCDEG prior to data collection.

\section{Sample and sampling}

The actual sample included in this study was 1,106 type 2 diabetic patients. The target population is type 2 diabetic patients, and the accessible population was type 2 diabetic patients attending the NCDEG. The sample was selected using non-probability sampling technique. Accessible patients were included in the study if they met inclusion criteria: type 2 diabetic patients, age 18 years or above, and who agree to give informed consent to participate in the study. Exclusion criteria included: pregnant women, age $<18$ years, patients diagnosed with secondary RH (obstructive sleep apnea, primary aldosteronism and renal parenchymal disease), and patients who could not give informed consent.

\section{Data collection procedure}

Data including socio-demographic data such as age, gender, education level, smoking habits, monthly income, medical health insurance, a marital status, and region where the patient lives were collected using a pre-prepared data collection sheet directly from the patients and patient medical files. Self-reported medication adhered to exclude non-adherent patients. Data obtained from patient medical files were: diabetes duration, history of hypertension and its duration if present, anti-hypertensive medications, history of dyslipidemia and anti-dyslipidemic medication, history of CVD (coronary artery disease (CAD), stroke, chronic heart failure (CHF), and myocardial infarction (MI)) event and history of diabetes complications such as retinopathy, weight, height, body mass index (BMI), blood pressure, HbA1c, and kidney function test (KFT).

\section{Data management and analysis}

Data were managed and analyzed using Statistical Package for Social Science (SPSS) version 20. Values of continuous variables such as age, HbA1c, and duration of type 2 diabetes mellitus were described as mean \pm standard deviation (SD). Categorical variables were expressed as percentages; Chi-square test was used to compare categorical variable differences. Logistic regression was performed to adjusted odds ratio (OR) and $\mathrm{P}$-value of $<0.05$ was considered statistically significant.

\section{Results}

A total of 880 out of 1,106 type 2 diabetic patients had HTN with a mean age of 61.57 (SD: 9.56) and their age ranged from 31 to 87 years. Fifty-one percent (441) were in the age group of 50 - 65 years. About 55.3\% (487) were females. Most of hypertensive patients $(93 \%, 818)$ were married. Mean duration of hypertension was 9.23 years (SD: 7.65), with 46.5\% (409) having HTN for more than 10 years or more, while $56.3 \%$ (459) had uncontrolled blood pressure. More than half of the hypertensive patients $(65.8 \%, 579)$ were obese, $28.8 \%(244)$ were overweight, and $52.5 \%$ (462) had diabetes duration $\geq 10$ years. More than half of hypertensive patients $(68.2 \%, 600)$ had uncontrolled blood sugar. In regard to diabetes medications, 48.3\% (425) were on oral hypoglycemic agents (OHA), $3.9 \%$ (34) were on insulin only and $47.8 \%$ (421) were on both (OHA and insulin treatment). Most patients had diabetes comorbidities including $85.8 \%$ (755) having dyslipidemia, $50.3 \%$ (396) having high triglyceride, and 29\% (255) having CVD. Retinopathy was present in $16.8 \%$ (148) and $25.1 \%$ (193) had impaired kidney function (glomerular filtration rate (GFR) $<90 \mathrm{~mL} / \mathrm{min}$ ).

\section{Prevalence of RH}

The overall prevalence of $\mathrm{RH}$ among diabetic patients with HTN was $16 \%$ (141/880). RH was higher among females $(53 \%, 74 / 141)$ than males with no significant statistical difference. RH was significantly higher $(55 \%, 77 / 141)$ among age group $>65$ years $(P=0.000)$ than younger age group. As shown in Table 1, RH was significantly higher $(68.1 \%, 95 / 141)$ among patients with diabetic mellitus duration $\geq 10$ years $(\mathrm{P}$ 
Table 1. Distribution of Resistant Hypertension by Certain Clinical Data and Laboratory Variables Using Chi-Square Test $(\mathrm{N}=880)$

\begin{tabular}{|c|c|c|c|c|c|}
\hline \multirow[t]{2}{*}{ Characteristics } & \multicolumn{2}{|c|}{$\begin{array}{l}\text { Resistant hypertension } \\
\qquad(\mathrm{N}=141)\end{array}$} & \multicolumn{2}{|c|}{$\begin{array}{l}\text { Non-resistant hypertension } \\
\qquad(\mathrm{n}=739)\end{array}$} & \multirow[t]{2}{*}{ P value } \\
\hline & $\mathbf{N}(\%) *$ & $\% * *$ & $\mathbf{N}(\%)^{*}$ & $\% * *$ & \\
\hline BMI & & & & & 0.014 \\
\hline Normal & $4(7)$ & 2.8 & $53(93)$ & 7.2 & \\
\hline Overweight & $30(12.3)$ & 21.3 & $214(87.7)$ & 29 & \\
\hline Obese & $107(18.5)$ & 75.9 & $472(81.5)$ & 63.8 & \\
\hline DM duration & & & & & 0.000 \\
\hline$<5$ years & $17(8.9)$ & 12.1 & $174(91.1)$ & 23.5 & \\
\hline $5-9$ years & $28(12.3)$ & 19.9 & $199(87.7)$ & 26.9 & \\
\hline$>10$ years & $96(20.8)$ & 68.1 & $366(79.2)$ & 49.5 & \\
\hline Hypertension duration & & & & & 0.000 \\
\hline$<5$ years & $7(2.6)$ & 5 & $258(97.4)$ & 34.9 & \\
\hline $5-9$ years & $29(14.8)$ & 20.6 & $167(85.2)$ & 22.6 & \\
\hline$>10$ years & $105(25.1)$ & 74.5 & $314(74.9)$ & 42.5 & \\
\hline $\mathrm{HbA1c}$ & & & & & 0.200 \\
\hline Controlled A1C $<7$ & $38(13.6)$ & 27 & $242(86.4)$ & 67.3 & \\
\hline Uncontrolled $\mathrm{A} 1 \mathrm{C} \geq 7$ & $103(17.2)$ & 73 & $497(82.8)$ & 32.7 & \\
\hline Hypertension controlling & & & & & 0.000 \\
\hline Controlled BP & $30(7.8)$ & 21.3 & $355(92.2)$ & 48 & \\
\hline Uncontrolled BP & $111(22.4)$ & 78.7 & $384(77.6)$ & 52 & \\
\hline Dyslipidemia & & & & & 0.002 \\
\hline Yes & $132(17.5)$ & 93.6 & $632(82.5)$ & 93.6 & \\
\hline No & $9(7.2)$ & 6.4 & $116(92.8)$ & 6.4 & \\
\hline Retinopathy & & & & & 0.004 \\
\hline Yes & $36(24.3)$ & 25.5 & $112(75.7)$ & 15.2 & \\
\hline No & $105(14.3)$ & 74.5 & $627(85.7)$ & 84.8 & \\
\hline CVD & & & & & 0.000 \\
\hline Yes & $77(30.2)$ & 54.6 & $178(69.8)$ & 75.9 & \\
\hline No & $64(10.2)$ & 45.4 & $561(89.8)$ & 24.1 & \\
\hline DM medication & & & & & 0.001 \\
\hline OHA & 48 (11.3) & 43 & 377 (88.7) & 51 & \\
\hline Insulin only & $8(23.5)$ & 5.7 & $26(76.5)$ & 3.5 & \\
\hline Both & $83(20.2)$ & 60.3 & $336(79.8)$ & 45.5 & \\
\hline GFR & & & & & 0.025 \\
\hline$>90$ & $111(19.5)$ & 84.7 & $458(80.5)$ & 72.6 & \\
\hline $90-60$ & $13(9.2)$ & 9.9 & $128(90.8)$ & 20.3 & \\
\hline $59-30$ & $6(12.5)$ & 4.6 & $42(87.5)$ & 6.7 & \\
\hline $29-15$ & $1(25)$ & 0.8 & $3(75)$ & 0.5 & \\
\hline
\end{tabular}

$=0.000)$. Regarding glycemic control, $\mathrm{RH}$ was higher $(73 \%$, $103 / 141)$ among uncontrolled blood sugar patients with no significant association $(\mathrm{P}=0.084)$. Regarding HTN duration, RH was significantly higher $(74.5 \%, 105 / 141)$ among patients with HTN duration for 10 years or more $(\mathrm{P}=0.000)$ (Table 1). Also RH was significantly higher $(78.7 \%, 111 / 141)$ among uncontrolled blood pressure hypertensive patients $(\mathrm{P}=0.000)$. Similarly RH was significantly higher $(75.9 \%, 107 / 141)$ 
among obese patients $(\mathrm{P}=0.014)$. Regarding diabetes complication and comorbidities, RH was significantly higher $(93.6 \%$, $132 / 141)$ among patients with dyslipidemia $(\mathrm{P}=0.002)$ (Table $1)$, and RH was $25.5 \%(36 / 141)$ among patients with retinopathy $(\mathrm{P}=0.004)$. In addition, $\mathrm{RH}$ was $54.6 \%$ among patients with CVD with significant P-value (0.000), and also RH was $84.7 \%$ among stage $1,9.9 \%$ among stage $2,4.6 \%$ among stage 3 , and $0.8 \%$ among stage 4 with significant $P$ value $(0.025)$. Finally according to diabetes treatment regimen, $\mathrm{RH}$ prevalence was $43 \%$ among patients on OHA, 5.7\% among patients on insulin only and $60.3 \%$ among patients treated with insulin and OHA (P-value $=0.001)$ as shown in Table 1 . As shown in Table 1 , the results of this study showed that increasing in age, duration and controlling of HTN, obesity, and CVD are statistically significant associated factors.

\section{Discussion}

This study reported the overall prevalence of RH among type 2 diabetic hypertensive patients and it was $16 \%$, with no significant change in the prevalence between males and females $(\mathrm{P}=0.257)$. Previous epidemiologic studies indicated that the prevalence of $\mathrm{RH}$ among hypertensive population ranges from $10 \%$ to $30 \%$ [10]. Many studies reported that diabetes was a significant risk factor of RH occurrence among hypertensive patients [10, 12-21]. In comparing the results of this study with others which were conducted among hypertensive patients without type 2 diabetes, the prevalence of $\mathrm{RH}$ was higher. A Brazilian study conducted on 4,116 hypertensive patients reported that RH among hypertensive patients was 11\% [22], and the prevalence was nearly the same among American hypertensive adults which was $12.8 \%$ [14]. It was $8.8 \%$ among Chinese hypertensive patients [23], and the prevalence of $\mathrm{RH}$ was higher in our study result because our study concerns type 2 diabetic patients which is a significant risk factor for $\mathrm{RH}$. Prevalence of $\mathrm{RH}$ among diabetic patients was reported by a few studies; RIACE study reported that RH among type 2 diabetic patients was $17 \%$ in Spain [16]. Also 10\% was the prevalence of RH among Italian type 2 diabetes patients [17]. The result of this study was consistent with other studies conducted among diabetic patients.

The results of this study showed that increasing in age, duration and controlling of HTN, obesity, and CVD are statistically significant associated factors. It also is shown that older age patients were 1.8 times more likely to have RH. This result was consistent with several studies among hypertensive patients with or without diabetes. A Colombian study reported that increasing in age increased the risk to have $\mathrm{RH}$ (OR: 1.36) [13]. Besides, a study conducted in Japan showed that increasing age is significantly associated with $\mathrm{RH}(\mathrm{P}<$ 0.05) [19]. A study conducted in the Middle East, including 65,710 hypertensive patients, reported that elderly people were more able to have RH with a significant P-value of $<0.05$ [24]. Obesity is another important significant finding, which has a strongly positive association with RH. Obese patients, in this study, were four times more likely to have RH. Similarly, a study conducted in the Middle East showed that obesity had a positive significant relation with $\mathrm{RH}$ patients [21]. Also obese hypertensive patients in Californian and Colombia were more likely to have RH (OR: 1.46) and (OR: 1.84), respectively [13, 15]. The association between RH and obesity could be related to a fact that obese patients not only have more chance to get type 2 diabetes and HTN, but also they were more able to have uncontrolled blood pressure which is an important cause to increase the risk of having RH [11]. An additional important finding is that long-standing HTN was strongly associated with $\mathrm{RH}$, patients who had HTN duration $\geq 10$ years were nine times more likely to have RH with significant P-value (0.000); this finding agreed with several studies that reported long duration of HTN was associated significantly with RH (OR: 1.76 and 3.1 , respectively) $[12,13]$. Also, the result of this study showed that uncontrolled blood pressure leads to increased risk of having $\mathrm{RH}$ four times than controlled blood pressure hypertensive patients; this was in line with a retrospective study report which showed that uncontrolled blood pressure had a positive significant association with RH (OR: 1.3) [12]. And finally, CVD had significant association with $\mathrm{RH}$; our result showed that patients with CVD were 2.9 times more likely to have RH with significant P-value (0.000). This result was consistent with AHA report, RIACE study, and Presell et al $[10,14,15]$. Besides, other studies were conducted to assess the association of CVD with $\mathrm{RH}$; they reported that RH was a significant risk factor (OR: 1.3 and 2, respectively) $[19,25]$.

\section{Conclusion and recommendation}

The prevalence of $\mathrm{RH}$, among adult patients with type 2 diabetes, was $16 \%$. Older age, obesity, long duration and uncontrolled blood pressure and CVD were significantly associated with $\mathrm{RH}$ positively. $\mathrm{RH}$ is a common, serious problem which could worsen diabetes and HTN complication. Early detection of RH could help the patients and improve his health status; identifying the characteristics of patients who are more able to have RH will eventually lead to a significant improvement in the management of this health problem and prevent the adverse effect. This could be achieved by highlighting the need to improve the awareness and education for patients and medical staff, early diagnosis, diagnostic criteria, and intervention for RH. Type 2 diabetic hypertensive which is characterized by old age, obese, and long duration HTN should be screened for RH by regular assessment for patients' blood pressure controlling, proper treatment for HTN and body weight controlling.

\section{Limitations}

First, this is a cross-sectional study. It is not possible to clearly assess a cause and effect relationship between RH and the risk factors. Second, this study was conducted in one center and non-random sampling was used, and it may limit the generalization of the result. Also, our prevalence result was according to blood pressure reading during patients visit to the clinic, so the white coat effect could affect the result, and we needed to apply ambulatory $24 \mathrm{~h}$ blood pressure monitoring to exclude 
white coat effect.

\section{Strength}

This study has a number of strengths, including a large sample, a highly response rate, and validated measures of medication adherence, which were used to exclude patients with pseudo resistant who did not adhere to his medication and finally, this study was the first study conducted among diabetic patients in the Middle East. And up to my knowledge, there were a few studies conducted globally to assess the prevalence of $\mathrm{RH}$ among diabetic patients.

\section{References}

1. World Health Organization. The world health report 2002: reducing risks, promoting healthy life. World Health Organization; 2002.

2. Fatema K, Zwar NA, Milton AH, Rahman B, Ali L. Application of two versions of the WHO/international society of hypertension absolute cardiovascular risk assessment tools in a rural Bangladeshi population. BMJ Open. 2015;5(10):e008140.

3. Koju R, Manandhar K, Risal A, Steiner TJ, Holen A, Linde M. Undertreated Hypertension and its Implications for Public Health in Nepal: Nationwide Population-Based Survey. Kathmandu Univ Med J (KUMJ). 2015;13(49):37.

4. Nelaj E, Gjata M, Tase M. P-040: Relation of type 2 diabetes and hypertension, and their impact on cardiovascular risk. InAnnales de cardiologie et d'angeiologie. 2015;64:S37-S38. Elsevier Masson.

5. Kearney PM, Whelton M, Reynolds K, Muntner P, Whelton PK, He J. Global burden of hypertension: analysis of worldwide data. Lancet. 2005;365(9455):217-223.

6. Mubarak FM, Froelicher ES, Jaddou HY, Ajlouni KM. Hypertension among 1000 patients with type 2 diabetes attending a national diabetes center in Jordan. Ann Saudi Med. 2008;28(5):346-351.

7. UK Prospective Diabetes Study Group. Tight blood pressure control and risk of macrovascular and microvascular complications in type 2 diabetes: UKPDS 38. BMJ. 1998;317(7160):703-713.

8. James PA, Oparil S, Carter BL, Cushman WC, Dennison-Himmelfarb C, Handler J, Lackland DT, et al. 2014 evidence-based guideline for the management of high blood pressure in adults: report from the panel members appointed to the Eighth Joint National Committee (JNC 8). JAMA. 2014;311(5):507-520.

9. Colosia AD, Palencia R, Khan S. Prevalence of hypertension and obesity in patients with type 2 diabetes mellitus in observational studies: a systematic literature review. Diabetes Metab Syndr Obes. 2013;6:327-338.

10. Calhoun DA, Jones D, Textor S, Goff DC, Murphy TP, Toto RD, White A, et al. Resistant hypertension: diagnosis, evaluation, and treatment. A scientific statement from the American Heart Association Professional Education
Committee of the Council for High Blood Pressure Research. Hypertension. 2008;51(6):1403-1419.

11. de la Sierra A, Segura J, Banegas JR, Gorostidi M, de la Cruz JJ, Armario P, Oliveras A, et al. Clinical features of 8295 patients with resistant hypertension classified on the basis of ambulatory blood pressure monitoring. Hypertension. 2011;57(5):898-902.

12. Daugherty SL, Powers JD, Magid DJ, Tavel HM, Masoudi FA, Margolis KL, O'Connor PJ, et al. Incidence and prognosis of resistant hypertension in hypertensive patients. Circulation. 2012;125(13):1635-1642.

13. Kumara WN, Perera T, Dissanayake M, Ranasinghe P, Constantine GR. Prevalence and risk factors for resistant hypertension among hypertensive patients from a developing country. BMC research notes. 2013;6(1):1.

14. Persell SD. Prevalence of resistant hypertension in the United States, 2003-2008. Hypertension. 2011;57(6):1076-1080.

15. Sim JJ, Bhandari SK, Shi J, Liu IL, Calhoun DA, McGlynn EA, Kalantar-Zadeh K, et al. Characteristics of resistant hypertension in a large, ethnically diverse hypertension population of an integrated health system. Mayo Clin Proc. 2013;88(10):1099-1107.

16. Solini A, Zoppini G, Orsi E, Fondelli C, Trevisan R, Vedovato $\mathrm{M}$, Cavalot $\mathrm{F}$, et al. Resistant hypertension in patients with type 2 diabetes: clinical correlates and association with complications. J Hypertens. 2014;32(12):24012410; discussion 2410.

17. Ciobanu DM, Kilfiger H, Apan B, Roman G, Veresiu IA. Resistant hypertension in type 2 diabetes: prevalence and patients characteristics. Clujul Med. 2015;88(3):327-332.

18. Adler AI, Stratton IM, Neil HA, Yudkin JS, Matthews DR, Cull CA, Wright AD, et al. Association of systolic blood pressure with macrovascular and microvascular complications of type 2 diabetes (UKPDS 36): prospective observational study. BMJ. 2000;321(7258):412-419.

19. Yokoyama H, Araki S, Watanabe S, Honjo J, Okizaki S, Yamada D, Shudo R, et al. Prevalence of resistant hypertension and associated factors in Japanese subjects with type 2 diabetes. Diabetes Res Clin Pract. 2015;110(1):1825.

20. Girerd X, Rosenbaum D, Villeneuve F. [Resistant hypertension: evaluation and treatment]. Presse Med. 2009;38(4):643-651.

21. Mussa BM, Abduallah Y, Abusnana S. Prevalence of Hypertension and Obesity among Emirati Patients with Type 2 Diabetes. Journal of Diabetes \& Metabolism. 2016.

22. Lotufo PA, Pereira AC, Vasconcellos PS, Santos IS, Mill JG, Bensenor IM. Resistant hypertension: risk factors, subclinical atherosclerosis, and comorbidities among adults-the Brazilian Longitudinal Study of Adult Health (ELSA-Brasil). J Clin Hypertens (Greenwich). 2015;17(1):74-80.

23. Chia YC, Ching SM. Prevalence and predictors of resistant hypertension in a primary care setting: a crosssectional study. BMC Fam Pract. 2014;15:131.

24. Weitzman D, Chodick G, Shalev V, Grossman C, Grossman E. Prevalence and factors associated with resistant hypertension in a large health maintenance organization 
in Israel. Hypertension. 2014;64(3):501-507.

25. Sim JJ, Bhandari SK, Shi J, Reynolds K, Calhoun DA, Kalantar-Zadeh K, Jacobsen SJ. Comparative risk of re- nal, cardiovascular, and mortality outcomes in controlled, uncontrolled resistant, and nonresistant hypertension. Kidney Int. 2015;88(3):622-632. 